\title{
Implant-supported Overdenture
}

\author{
${ }^{1}$ Kuntal S Kadam, ${ }^{2}$ Shankar P Dange, ${ }^{3}$ Kishore Mahale, ${ }^{4}$ Smita A Khalikar, ${ }^{5}$ Arun Khalikar
}

\begin{abstract}
Edentulous patients often experience problems with their mandibular complete dentures. Patients with the resorbed mandibular ridge often complain of lack of stability and retention of the mandibular denture, together with a decreased chewing ability. While implant-supported fixed prosthesis offers many advantages, they are very expensive and not indicated in many conditions. Implantsupported removable prosthesis can be a choice of treatment in such cases. This clinical report describes a method to rehabilitate a patient with resorbed mandibular ridge with implant-supported overdenture.
\end{abstract}

Keywords: Implant, Restoration, Tooth replacement.

How to cite this article: Kadam KS, Dange SP, Mahale K, Khalikar SA, Khalikar A. Implant-supported Overdenture. Int J Oral Implantol Clin Res 2017;8(1):22-25.

Source of support: Nil

Conflict of interest: None

\section{INTRODUCTION}

Edentulous patients often experience problems with their mandibular complete dentures. Patients with the resorbed mandibular ridge often complain of lack of stability and retention of the mandibular denture, together with a decreased chewing ability. ${ }^{1}$ Insertion of implants creates more favorable environment for the restoration in such patients. Implant-supported prostheses options for an edentulous arch include implant-supported fixed prosthesis and implant-supported removable prosthesis. While implant-supported fixed prosthesis offers many advantages like being esthetically pleasing and feels being actually like natural dentition, they are very expensive and not indicated in many conditions. ${ }^{2}$ Implantsupported removable prosthesis offers certain advantages over implant-supported fixed restoration. ${ }^{2}$ Many patients are satisfied with a stable implant-supported overdenture that requires limited clinical time and financial expense. ${ }^{1}$

${ }^{1}$ Postgraduate Student, ${ }^{2}$ Dean and Professor, ${ }^{3}$ Professor and Head, ${ }^{4,5}$ Associate Professor

${ }^{1-5}$ Department of Prosthodontics, Government Dental College and Hospital, Aurangabad, Maharashtra, India

Corresponding Author: Kuntal S Kadam, Postgraduate Student, Department of Prosthodontics, Government Dental College and Hospital, Aurangabad, Maharashtra, India, Phone: +919422504343, e-mail: drkuntalkadam@gmail.com
This clinical report describes a method to rehabilitate a patient with resorbed mandibular ridge with implantsupported overdenture.

\section{CASE REPORT}

A 49-year-old female reported to the Department of Prosthodontics, Government Dental College and Hospital, Aurangabad, India, with the chief complaint of difficulty in chewing food and loose-fitting lower denture. Patient had been edentulous since past 1.5 years due to extraction of periodontally compromised and carious teeth. She had been using a set of complete dentures for past 6 months and was not satisfied as lower denture was not stable and fitting well. Clinical examination revealed edentulous maxillary and mandibular ridges with class I ridge relation (Fig. 1). Mandibular ridge was resorbed (Atwoods class IV).

Patient was informed about various treatment options available. Implant-supported fixed prosthesis could not be planned as lip support and esthetics would not be improved. As patient was primarily concerned about retention of the dentures, it was decided to rehabilitate the patient using mandibular implant-supported overdenture opposing maxillary complete denture.

Diagnostic impressions were made. Diagnostic orthopantomogram (OPG) and casts, records were studied. Implant placement was planned at B and D positions after obtaining consent from patient (Misch's overdenture options-OD1). ${ }^{2}$ Treatment was divided into three phases: (1) diagnostic denture fabrication, (2) implant placement, and (3) final prosthesis fabrication.

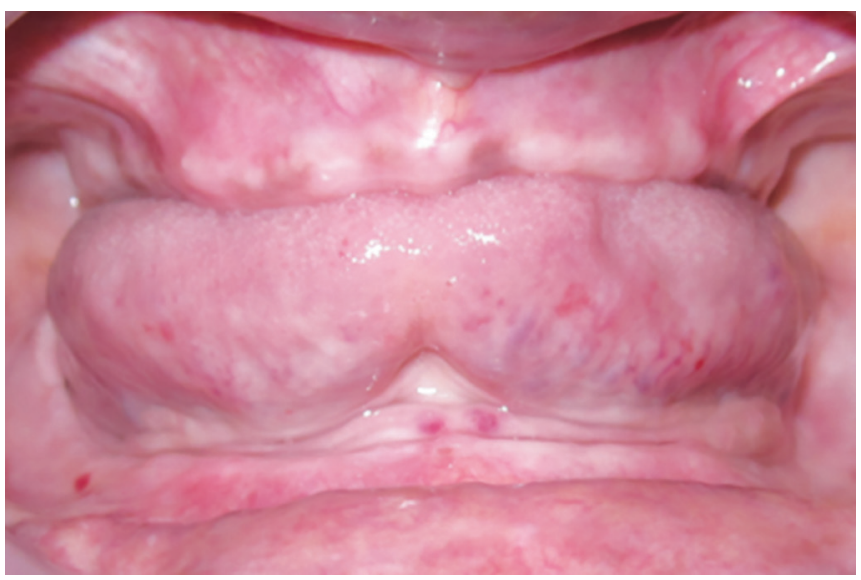

Fig. 1: Preoperative intraoral view 


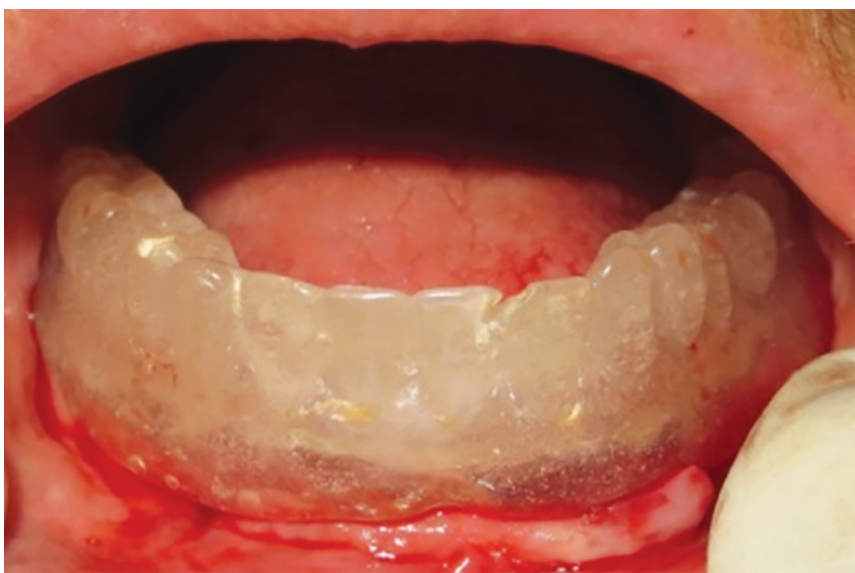

Fig. 2: Surgical stent placed intraorally

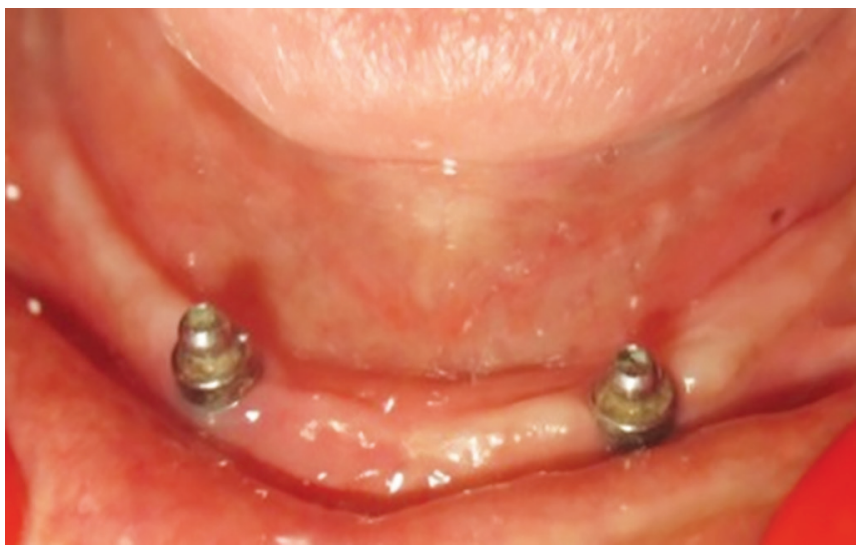

Fig. 4: Solitary ball attachment incorporated

\section{Diagnostic denture fabrication}

Diagnostic denture was fabricated using conventional steps for denture fabrication. It was used to analyze the space available for overdenture attachment and fabrication of radiographic stent, which was later to be used as a surgical stent (Fig. 2).

\section{Implant placement}

Cone beam computed tomography analysis was done. Two implants of $4.2 \times 10 \mathrm{~mm}$ were placed at B and D positions. Stage II surgery was carried out after 3 months with radiographic and clinical evidence of healing (Fig. 3). Healing abutments were placed. After soft tissue healing prefabricated single ball abutments were attached (Fig. 4).

\section{Final prosthesis fabrication}

Two weeks after placement of healing abutments, primary impression was made using irreversible hydrocolloid impression material. Maxillary final impression was made using conventional technique. For mandibular final impression, custom tray was fabricated and window was created for splinted open tray pickup/direct impression of implants. Border molding was completed. Then, open

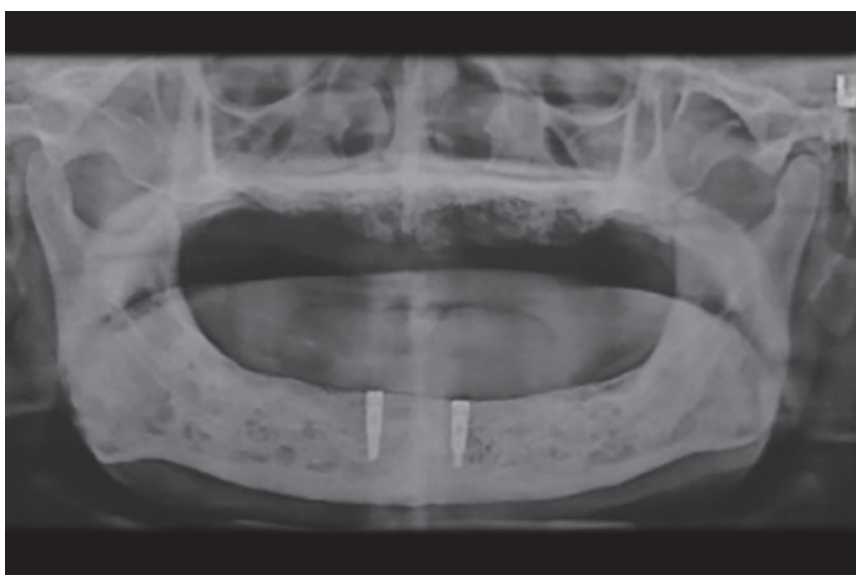

Fig. 3: OPG after healing

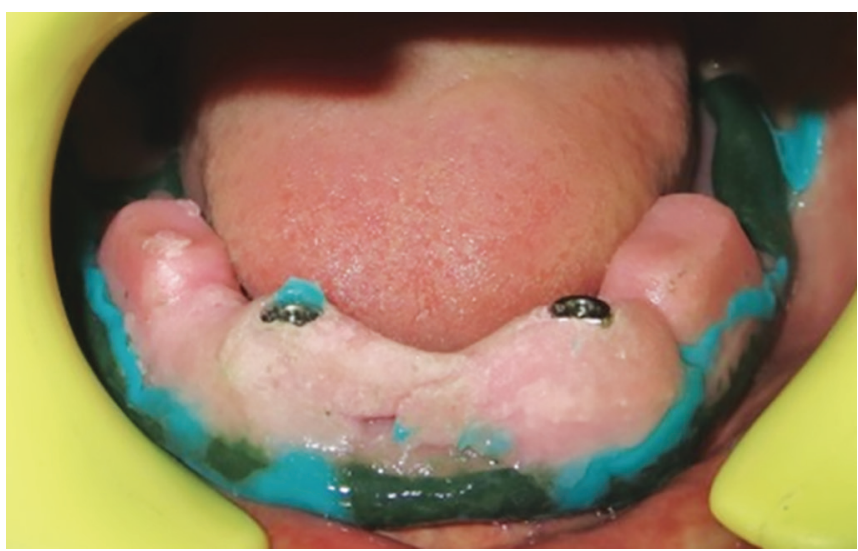

Fig. 5: Impression copings splinted with acrylic resin

tray impression copings were placed over implants. Low-viscosity polyvinyl siloxane was loaded in the tray. Impression copings were splinted using self-cure acrylic resin. After complete polymerization, the copings were loosened and tray was removed (Figs 5 and 6). Definitive casts were made.

Autopolymerizing acrylic resin was used to fabricate denture bases over the definitive cast. Using face bow record, upper cast was mounted and then centric relation was recorded. Bilateral balanced occlusion scheme was used for teeth arrangement. Try-in was done. Retentive metal housings were incorporated by an indirect method. For this, after dewaxing, ball abutment analogs were attached to the cast. Metal housing with retentive rings were placed over analogs and denture was processed. Denture finishing and polishing were done in a conventional manner.

The prosthesis was delivered and patient was instructed about the aftercare and recall schedule (Figs 7 and 8).

\section{DISCUSSION}

Overdenture is defined as any removable dental prosthesis that covers and rests on one or more remaining natural teeth, the roots of natural teeth, and/or dental 

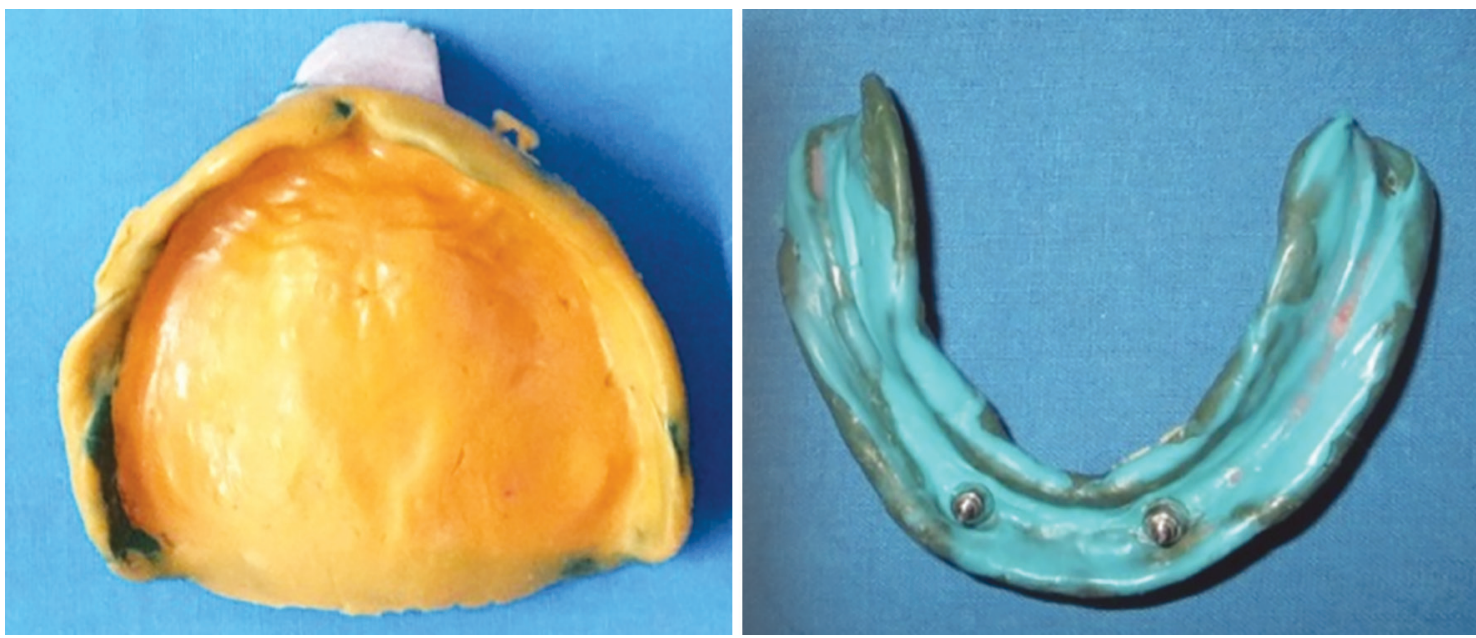

Fig. 6: Final impression

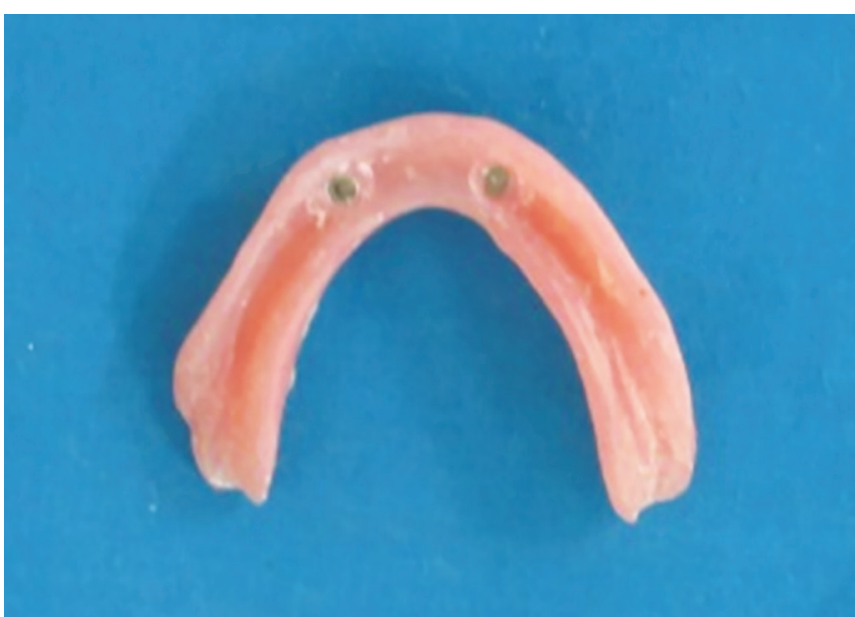

Fig. 7: Intaglio surface of processed denture showing incorporated stainless steel housings with white retentive caps

implants; a dental prosthesis that covers and is partially supported by natural teeth, natural tooth roots, and/or dental implant (Glossary of Prosthodontic Terms 8). If an edentulous patient is willing to remain with a removable prosthesis, an overdenture is often the treatment of choice. ${ }^{2}$ Implant-supported overdentures provide a good opportunity for dentists to improve the quality-of-life and oral health of the patient. ${ }^{3}$ The chewing efficiency with an implant-supported overdenture is improved by almost $20 \%$ compared with a traditional complete denture. ${ }^{2}$ The primary indication for a mandibular implant-supported overdenture is problems often found with mandibular dentures, such as lack of retention or stability, decrease in function, difficulty in speech, tissue sensitivity, and soft tissue abrasion. ${ }^{2}$ A number of implants incorporated are to be selected according to specific clinical and individual needs of the patient. ${ }^{4}$ In this case, two implant-supported mandibular prosthesis was planned taking into consideration anatomical features, patient's expectations, and the cost factor. The choice of attachment depends upon the retention required, jaw anatomy, interridge distance, overlying mucosa, oral function, and patient compliance for recall. ${ }^{3}$ Single attachments have following advantages: ${ }^{5}$

- Less costly

- Less technique-sensitive

- Easier to clean ${ }^{6}$
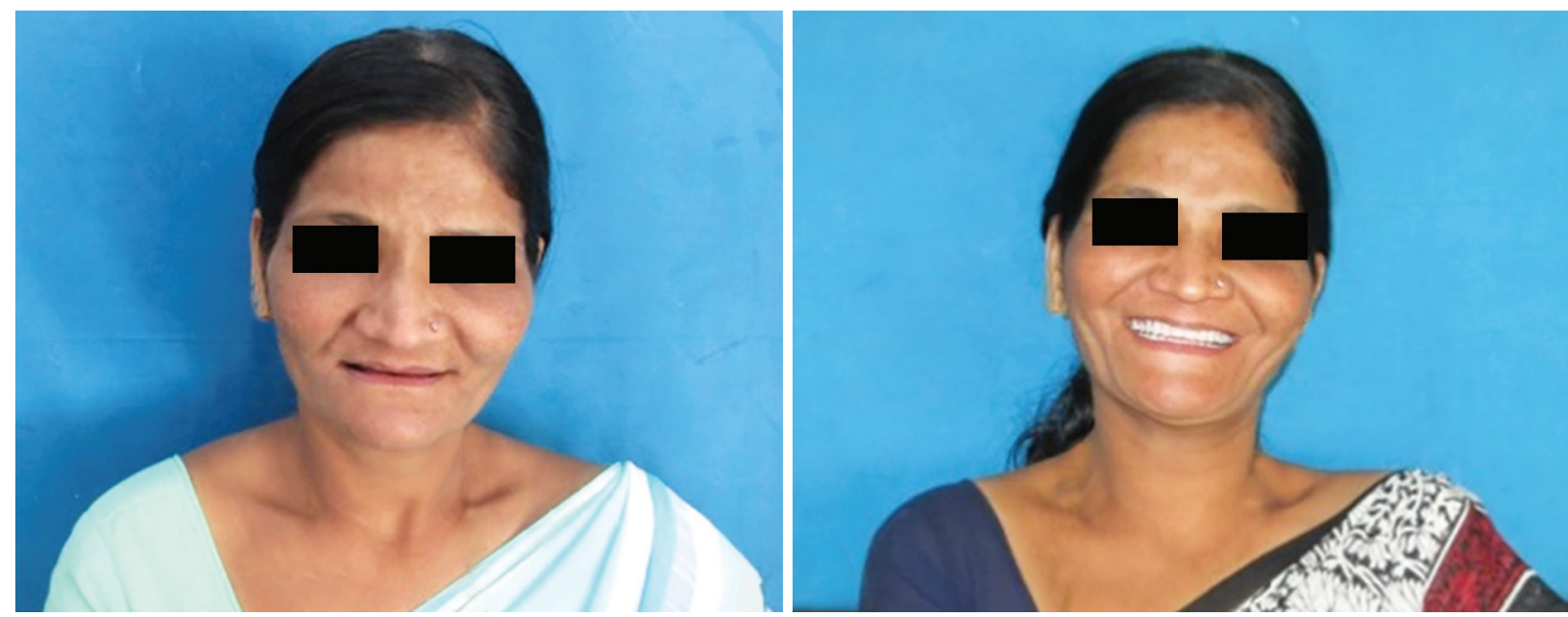

Fig. 8: Preoperative and postoperative extraoral view 
Opposing arch condition influences the choice of occlusal concept. Most practitioners have recommended a balanced occlusion for the patient with an edentulous maxilla opposing implant-supported overdenture. ${ }^{7}$

Most patients seeking improvement in the retention and stability of the mandibular denture and decrease of oral soreness have no objections to removable prostheses and do not desire complete fixed prostheses and their implied more difficult oral hygienic procedures. ${ }^{1}$

\section{SUMMARY}

This case report presents a novel treatment option to rehabilitate an edentulous patient with a resorbed mandibular ridge. Implant-supported overdenture proves to be a better treatment alternative to the conventional denture. Hence, this treatment modality should be practiced whenever indicated. It will preserve hard and soft tissues of the patient and give psychological relief to the patient, which he expects from the dental treatment.

\section{REFERENCES}

1. Batenburg RH, Meijer HJ, Raghoebar GM, VissinkA. Treatment concept for mandibular overdentures supported by endosseous implants: a literature review. Int J Oral Maxillofac Implants 1998 Jul-Aug;13(4):539-545.

2. Misch CE. Contemporary implant dentistry. Implant Dent 1999;8(1):90.

3. Cakarer S, Can T, Yaltirik M, Keskin C. Complications associated with the ball, bar and locator attachments for implantsupported overdentures. Med Oral Patol Oral Cir Bucal 2011 Nov 1;16(7):953-959.

4. Mericske-Stern R. Treatment outcomes with implant-supported overdentures: clinical considerations. J Prosthet Dent 1998 Jan;79(1):66-73.

5. Prasad DK, Prasad DA, Buch M. Selection of attachment systems in fabricating an implant supported overdenture. J Dent Implants 2014;4(2):177-181.

6. Sadowsky SJ. Mandibular implant-retained overdentures: a literature review. J Prosthet Dent 2001 Nov;86(5):468-473.

7. Wismeijer D, van Waas MA, Kalk W. Factors to consider in selecting an occlusal concept for patients with implants in the edentulous mandible. J Prosthet Dent 1995 Oct;74(4): 380-384. 